\title{
Monitoring the Suspension of Surgical Procedures
}

Desiré Carlos Callegari ${ }^{1}$, Hermes Melo Teixeira Batista ${ }^{1,2}$, Gylmara Bezerra de Menezes Silveira1, Iratyenne Maia da Silva Bentes ${ }^{1}$, Regina Petrola Bastos Rocha ${ }^{3}$, Leonardo Araújo Sampaio1, João Antônio Correa²

\section{Abstract}

Introduction: A surgical suspension generates a series of hassles and dissatisfaction of the patient and his family. Preparations for surgery involve an entire remodeling of the professional, social and family schedule, as well as other factors such as expectations regarding the results and the fear of the unknown.

Objective: A quantification and identification of the reasons for surgical cancellations was realized for a better understanding and guidance to the leadership team's actions on this issue. Thus, their monitoring is important in the search for actions to make the surgery center's processes more effective, favoring possibilities for improvement in the quality of hospital services. This way, the objective of this research was to identify the main causes for the cancellations of surgical procedures.

Method: Study of documentary and retrospective type, quantitative, performed in the surgical center of a hospital in the city of Juazeiro do Norte, CE, Brazil. Data collection was performed through digital files of the 'syshosp' system used to record performed and suspended surgical procedures. Data were collected from January to December 2014 and analyzed using simplified statistics and presentation through a table.

Results: The justifications for cancellation of procedures related to the organizational aspects of the institution were highlighted as main reasons for surgical suspension: the priority for urgency, lack of material resources/equipment required for the surgical procedure and no hospitalization of surgical patients. There were also those related to the lack of staff, being most of them because of the surgeon's inability to attend and absence of anesthesiologist causing the impossibility of building the surgical team. Finally, the suspensions regarding
1 Hospital Regional do Cariri - Juazeiro do Norte/Ce-Brazil.

2 Programa de Pós-graduação. Faculdade de Medicina do ABC. Santo André/São Paulo. Brazil.

3 Hospital e Maternidade São Francisco de Assis, São Camilo - Crato/Ce-Brazil.

Contact information:

Hermes Melo Teixeira Batista.

”' hermesmelo@oi.com.br 
priority for emergencies are highlighted. It was observed that the main determinants for surgical suspensions were those related to the organization of the hospital, with a total of 267 (51.1\%), standing out among these: technical problems (16.1\%), no admission (42,3\%), lack of material (13.5\%) and the priority for urgency (21\%).

Discussion: The Brazilian Ministry of Health (Ministério da Saúde) defines the surgery suspension rate by the number of suspended surgeries divided by the total of scheduled surgeries in a given period and multiplied by 1003. During the studied period, there were 6591 scheduled surgeries 6069 surgeries were performed and there were 522 suspensions. Thus, the overall average rate of suspension obtained was $7.9 \%$. Compared to other studies and the goals of the institution $(5 \%)$, it is clear that this is a high rate, but manageable.

Conclusion: It was observed that the suspensions of surgeries must be carefully monitored and analyzed by the entire team involved in order to disseminate this indicator and its possible consequences to all. The process of identification of consequences is still weak and needs to be strengthened to an effective action plan. It was revealed that the main cause of surgical cancellations during the surveyed year was related to the organization of the hospital, emphasizing the importance of updating the interaction of processes with the sectors that influence this indicator and preparation of strategic planning with everybody's involvement so you can minimize the data, as it directly affect the patient, professionals and the hospital, resulting from the patient's dissatisfaction to the longer permanency of the patient in hospital.

\section{Keywords}

Cancellation, surgical map, surgery.

\section{Introduction}

The surgery requires prior preparation of the patient and his/her family, since it involves acceptance of surgery, physical and psychological preparation, lifestyle interference, socioeconomic changes caused by absence from work, besides the stress situation caused by the fear of the unknown and the inherent dependence to the immediate postoperative period [1].

The issue of the suspension of elective surgeries has been widely studied in recent decades and the rates vary from $5.1 \%$ to $69.03 \%$. The most important aspects are inherent to the health institution. $[1,2]$

This is an event that should be examined from three perspectives, the first focused on the repercussions involving the patient/family, which interfere with the result of the assistance and service productivity; the second, from the consequences they cause to the multidisciplinary team, because they interfere with the work operationalization, time consumption and material resources; and fi- 
nally to the repercussions that involve the health institution with regards to its cost growth when you lose the opportunity to include other patient in the operating room, with underutilization of available resources, besides it increases the length of stay in the hospital environment [3].

In fact, there should be no surgery suspension, because the patient expects to have their health needs assisted and the service must be prepared to meet these expectations. However, many situations can contribute to the negative outcome at the expense of measures taken by the institution, as in the case of patients who develop deteriorating clinical conditions, even after assessment and preoperative surgical preparation. Each institution should establish measures to reduce the rate of surgery cancellation in their service, based on the main causes identified.

It is revealed, therefore, that surgery suspensions bring many losses to hospital care, since the surgical program involves important steps involving patient safety and the risks of surgery. This rate is an indicator of process quality.

After the appearance of these new concerns with safety and quality, according to the prevention of surgical infection manual from CDC (1999), it is suggested that the hospital stay is as short as possible while allowing the adequate preparation of the patient. One of the consequences from cancellation of surgeries is the increase in the patient's stay, increasing the risk of infection of the surgical site [4].

With the increase of technology in the hospital area, there was an increase on the need for better management about the risks for the patient, especially in the surgical center, sector with more complex procedures. Quantification and identification of the reasons for surgical cancellations were realized for a better understanding and guidance to the leadership team's actions on this issue.

Thus, their monitoring is important in the search for actions to make the surgery center's processes more effective, favoring possibilities for improvement in the quality of hospital services. This way, the objective of this research was to identify the main causes for the cancellations of surgical procedures.

\section{Method}

The study was characterized as exploratory, descriptive, with a quantitative approach, performed in a hospital unit at Juazeiro do Norte, CE, Brazil, characterized as highly complex covering several surgical specialties, highlighting: general surgery, orthopedics, trauma, vascular, plastic and others.

The admission of the patients in the surgical center is performed in three ways: care of hospitalized patients, admitted by the surgical clinic or by the emergency sector, with scheduling of elective surgeries from 7AM to 7PM, Monday to Friday.

Data collection was conducted from February to March 2015, after the approval from the institution and the Ethics Committee. The project was submitted to the Center of Studies of the hospital in question and submitted to the Plataforma Brasil.

Data analysis was demonstrated by a board and compared to the relevant literature. The casuistry of the study consists of all elective surgeries that were canceled in the period from January to December 2014.

The instrument used to collect the data was the map of surgery and an institutional structured form with the cause for surgery suspension given by nurses, surgeon and anesthesiologist.

The ethical principles were respected, according to the Resolution 466/12 of the Ministério da saúde (Ministry of Health), the Conselho Nacional de Saúde (National Health Council) and other Guidelines and Norms Regulating Research Involving Human Beings, as well as, the confidentiality of the identity of the participants was respected. All data were collected solely by the researcher in order 
to have uniformity in this collection, in the period between February and March 2015. [4]

\section{Results}

The main causes for cancellation of surgeries are related to the organization of the hospital, and, of these cancellations, $42.3 \%$ of customers were never hospitalized. The most prevalent cause found was the no hospitalization of the patient, and nowadays this fits in failure related to the organization of the unit, as fragility of our processes can still be found, because the lack of vacancies in the institution for the admission of elective surgery patients $(21.6 \%)$ is part of this cause.

Nowadays, the cancellation of surgeries must be carefully measured for a better analysis of this indicator, because failures in surgical planning (surgery map) can be minimized by offering a better assistance to surgical patients, reducing the impact and repercussions for the patient, professional and institution.

Table 1. Major causes for surgery suspensions. Juazeiro do Norte, CE, Brazil, 2015.

\begin{tabular}{|c|c|c|c|c|c|c|c|c|c|c|c|c|c|}
\hline Reasons For Suspensions & Jan & Feb & Mar & Apr & May & Jun & Jul & Aug & Sep & Oct & Nov & Dec & Total \\
\hline \multicolumn{14}{|l|}{ Related To The Patient } \\
\hline Patient Was Fed & 0 & 0 & 1 & 0 & 1 & 0 & 1 & 1 & 2 & 1 & 0 & 0 & 7 \\
\hline $\begin{array}{l}\text { Discharge Asked By The } \\
\text { Patient }\end{array}$ & 0 & 0 & 0 & 0 & 0 & 0 & 0 & 0 & 3 & 0 & 0 & 1 & 4 \\
\hline Patient Died & 2 & 0 & 0 & 0 & 0 & 0 & 0 & 0 & 1 & 0 & 1 & 1 & 5 \\
\hline Clinical Conditions & 6 & 15 & 12 & 4 & 9 & 9 & 4 & 8 & 11 & 5 & 6 & 18 & 107 \\
\hline Total & & & & & & & & & & & & & 123 \\
\hline \multicolumn{14}{|c|}{ Related To The Organization Of The Unit } \\
\hline Technical Problems & 0 & 1 & 0 & 3 & 0 & 4 & 15 & 4 & 7 & 1 & 2 & 2 & 43 \\
\hline Patient Not Admitted & 2 & 7 & 7 & 11 & 13 & 9 & 14 & 11 & 22 & 8 & 7 & 2 & 113 \\
\hline Lack Of Tests & 3 & 1 & 0 & 0 & 0 & 1 & 0 & 1 & 3 & 0 & 1 & 0 & 10 \\
\hline Resources Shortage & 0 & 2 & 1 & 2 & 1 & 16 & 4 & 5 & 0 & 0 & 2 & 3 & 36 \\
\hline Blood Shortage & 0 & 3 & 1 & 1 & 0 & 0 & 0 & 1 & 1 & 1 & 0 & 0 & 8 \\
\hline Lack Of Vacancy In The Icu & 0 & 0 & 0 & 0 & 0 & 0 & 0 & 0 & 0 & 0 & 0 & 0 & 0 \\
\hline Priority For Urgent Cases & 3 & 2 & 3 & 5 & 0 & 3 & 7 & 14 & 6 & 6 & 0 & 7 & 56 \\
\hline Extensive Elective Map & 0 & 0 & 0 & 1 & 0 & 0 & 0 & 0 & 0 & 0 & 0 & 0 & 1 \\
\hline Total & & & & & & & & & & & & & 267 \\
\hline \multicolumn{14}{|l|}{ Related To Human Resources } \\
\hline Absence Of Surgeon & 0 & 1 & 1 & 2 & 3 & 7 & 4 & 6 & 4 & 0 & 0 & 2 & 30 \\
\hline Absence Of Anesthesiologist & 5 & 0 & 2 & 1 & 9 & 3 & 3 & 7 & 4 & 5 & 3 & 0 & 42 \\
\hline $\begin{array}{l}\text { Prolongation Of Previous } \\
\text { Surgery }\end{array}$ & 0 & 2 & 0 & 2 & 1 & 3 & 5 & 8 & 5 & 4 & 5 & 3 & 35 \\
\hline Revaluation From The Surgeon & 0 & 1 & 0 & 0 & 0 & 1 & 0 & 0 & 1 & 2 & 0 & 1 & 6 \\
\hline Medical Decision & 0 & 4 & 2 & 1 & 1 & 0 & 3 & 4 & 0 & 2 & 2 & 0 & 19 \\
\hline Total & & & & & & & & & & & & & 132 \\
\hline
\end{tabular}

Source: Data Collection, 2015: Spreadsheet to track the suspension of surgeries from the surgical center of HRC. 


\section{Discussion}

During the studied period, 6591 elective surgeries of various specialties were scheduled, including general, orthopedic, oral and maxillofacial, plastic, vascular and neurosurgery, of which 522 (7.9\%) were canceled.

It was identified that the main causes for cancellation of surgeries are related to the organization of the unit, $21.6 \%$ of customers were never hospitalized and $10.7 \%$ were suspended because priority was given for cases of urgency. The main impediments for the admission were the absenteeism and the lack of vacancies for these elective procedures. In these cases the surgery is postponed to another time.

It is important to note that the study was conducted in an institution with emergency services and the booking is not limited to ambulatory patients, including those who are hospitalized and who have surgical indication. They are inserted on the map as scheduled emergencies, especially in the specialty of orthopedics, due to the great demand. This is weakening the processes of the surgical center, with the time increase in the hospitalization of these patients and the increase of complications, consequently, the patient's clinical condition tends to deteriorate.

The suspension of surgeries caused by priority given for patients with urgency $(10.7 \%)$ is found as the second leading cause for suspension and is related to the organization of the unit, which is responsible for a significant portion of the factors associated with the suspension, given that the priority for urgent cases is a recurring and inevitable event in institutions that cater to emergency care as is the case of the institution in this study.

There is a debilitation of the patient-health professionals-institution relationship when there is a surgery suspension. The main person harmed is the patient, who will have to go through the preoperative period again, with all the nuances involved for this moment. There is the fear of occurrence of problems in surgery, the delay to return to work and family life. Remembering that when preparing for surgery, the patient brings expectations with her him, doubts and fears about what will happen. All their worries and expectations are focused on the surgery and not on its suspension. It is a time of extreme fragility of the individual. [7]

In most institutions, the map of surgeries involves several professionals and support and healthcare sectors, people like surgeons, anesthesiologists, nurses, nursing technicians, as well as lots of specialized materials and equipment. The suspension of an operation is an important occurrence, but has not always received the necessary attention from the health team and the manager. Apparently, the cancelation of scheduled surgeries causes no concern to the multidisciplinary team in most health services; it is seen as routine, inherent to the organizational and functional structure of the institution [3].

The suspension of a surgery entails higher operational and financial costs, bringing negative consequences and discredit to the institution. The avoidance of all suspension of surgeries through a planned nursing care coordinated with the other professional teams and the development of an efficient administrative plan should be one of the goals of the nursing assistance team and administrative staff of the hospital. To provide a differentiated nursing care for the customer who had a suspended surgery, should be another concern for the professional [3].

It is important to mention that during the research we identified that the failure to prepare the preoperative patient was inserted within the causes in the justifications from the surgical team, causing the data to stay fragile for better analysis, because the cause has become not only inherent to the patient, but also to failure in the surgical process.

The number of suspended surgical procedures during the surveyed period was considerable (7.9\%), and among the causes, most suspensions were related to the patient, such as medical conditions and 
non-admission of the same at the facility. However, some events of the process can be worked through by the surgical team to minimize these cancellations.

The surgery involves several factors, from the client's preparation, organization of the surgical map, availability of materials and equipment as well as the allocation of human resources. Thus, when for some reason the suspension occurs, there is a failure in any of these processes or the settlement of an unforeseen event that cannot be modified.

The results of this study reveal that $4.8 \%$ of the scheduled procedures culminated in changes in behavior (revaluation), in other words they should not have been scheduled. This is a considerable number within the surgical department.

Thus, with the losses to client, family, multidisciplinary team and institution, the determinants for surgical cancellation must be properly monitored and restricted in the search to reduce these rates.

\section{Conclusion}

With the stated in mind, in order to eliminate or minimize the suspension of surgeries, the investigators conclude that there is the necessity for constant analysis of the causes for suspension, prior appointment by telephone with patients, uniformity of approaches from surgeons and anesthesiologists.

It is worth mentioning the importance of a preoperative nursing visit with a prior check of all client's preparation, such as: fasting, clinical conditions (laboratory tests), hemoderivatives reserve, availability of equipment and materials and specialized surgical team, as well as the proper production of the surgical map.

The research brought progress for this institution because it allowed the improvement of action plans targeting the fragility of the surgery schedule process. Nowadays, nine performance indicators of the surgical center process are followed and, among all, the monitoring of the surgery cancellation indicator is the most concerning, as it involves the most varied causes and reflects directly on the quality of care provided to patients. Huge challenges are faced by services that seek to provide safe care to the surgical patient and the decrease of suspensions is a goal that should be pursued by all the services involved, since the causes can be found in the pharmacy, sterile processing department, inpatient unit, nutrition and others.

It was observed that the suspensions of surgeries must be carefully monitored and analyzed by the entire team involved in order to disseminate this indicator and its possible consequences to all. The process for identification of consequences is still weak and needs to be strengthened to an effective action plan.

It was revealed that the main cause for surgical cancellations during the surveyed year was related to the organization of the hospital, emphasizing the importance of updating the interaction of processes with the sectors that influence this indicator and the preparation of strategic planning with everybody's involvement so you can minimize the data, as it directly affect the patient, professionals and the hospital, resulting from the patient's dissatisfaction to the longer permanency of the patient in the hospital. 


\section{References}

1. Bianchi ERF. Estudo exploratório sobre suspensão de cirurgia: a comunicação da suspensão e a reação relatada pelo paciente frente ao fato. [dissertação]. São Paulo:Escola de Enfermagem, Universidade de São Paulo; 1983.

2. Bomfim VO, Ferreira JBC. Análise do absenteísmo cirúrgico em hospital público. Rev. Baiana de Saúde Pública 2008; 32(2): 241 252.

3. Cavalcante JB, Pagliuca LMF, Almeida PC. Cancelamento de cirurgias programadas em um hospital-escola: estudo exploratório. Rev Lat Am Enferm. 2000; 8(4): 59-65.

4. Centers for disease control and prevention(CDC). Guideline for prevention of surgical site infection, 1999. Infect Control Hosp Epidemiol.1999; 20(4): 247-278. Disponível em: http://www. cdc.gov/hicpac/pdf/guidelines/SSI 1999.pdf.

5. Cervo, A.L; Bervian, P.A. Metodologia Cientifica. São Paulo: Prentice Hall, 2002

6. Figueiredo, Nébia Almeida de Método e metodologia na pesquisa cientificam $3^{a}$ e.d São Caetano do Sul, SP Yendis editora 2008.

7. Paschoal MLH, Gatto, MAF. Taxa de suspensão de cirurgias em um hospital universitário e os motivos de absenteísmo do paciente à cirurgia programada. Rev Lat Am Enferm. 2006; 14(1): 48-53.

8. Vieira, Maria Jésia; Furegato, Antonia Regina F. Suspensão de cirurgias: atitudes e representações dos enfermeiros. Rev. esc. enferm. USP, São Paulo, v. 35, n. 2, p. 135-140, June 2001. Disponível em: <http://www.scielo.br/scielo.php?script=sci arttext\&pid=S0080-62342001000200007\&lng=en\&nrm=iso > . Acesso em 25 Abril. 2015. http://dx.doi.org/10.1590/S0080$\underline{62342001000200007}$

\section{Comment on this article:}

\section{(f) [in $8+\mathbf{S}$.}

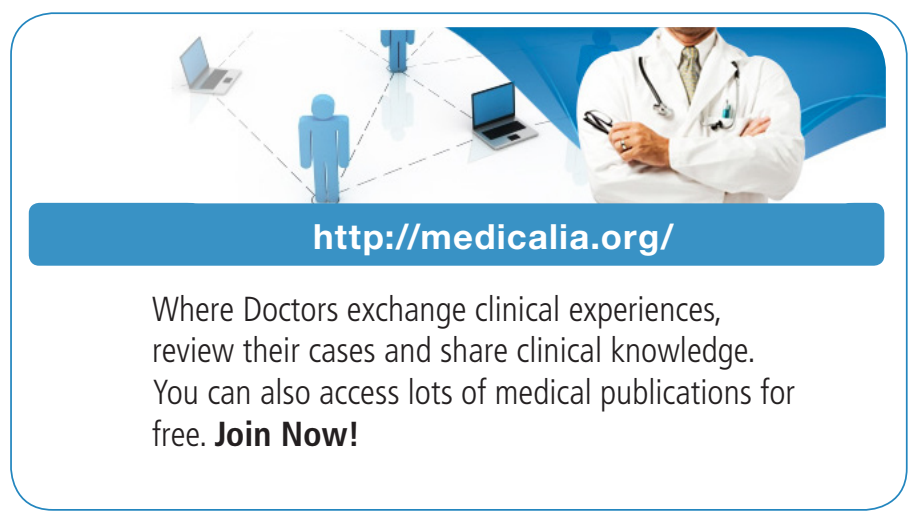

\section{Publish with iMedPub}

http://www.imed.pub

International Archives of Medicine is an open access journal publishing articles encompassing all aspects of medical science and clinical practice. IAM is considered a megajournal with independent sections on all areas of medicine. IAM is a really international journal with authors and board members from all around the world. The journal is widely indexed and classified Q1 in category Medicine. 